\title{
Improving Electricity Access in Ghana Challenges and the Way Forward
}

\author{
Aaron Yaw Ahali \\ Department of Economics and International Studies, the University of Buckingham, UK
}

Email address:

aofoee@gmail.com

To cite this article:

Aaron Yaw Ahali. Improving Electricity Access in Ghana Challenges and the Way Forward. International Journal of Energy and Power Engineering. Special Issue: Electricity Market. Vol. 5, No. 2-2, 2016, pp. 9-17. doi: 10.11648/j.ijepe.s.2016050202.12

\begin{abstract}
Growth in demographic requirements, increased urbanization and rural electrification coupled with an everincreasing technological demand, and the aspiration to transform into a middle-income country have led to a fast growth in energy demand in the past two decades in Ghana. Yet there is a huge deficit in supply and this has become a major limitation to growth and quality of life. As Ghana has devoted itself to universal access to electricity by 2020, the real challenge is in reaching the capacity to meet this goal; and most importantly, ensuring that supply is adequate and reliable. With access to electricity in Ghana been low for some time now with no improvement in sight, there is the need for a study such as this. The paper sought to examine the challenges preventing the progress of accessible electricity in Ghana. The paper adopted a systematic review approach and used publications that focused on or related to the subject understudy. Key findings identified in the paper include; poor pricing, increasing demand and supply shortfalls coupled with irregularities, institutional restrictions, lack of credible off-taker and lack of policy and project continuity. To address these challenges, suggested recommendations include; exploring all means of getting power source, including LNG, Solar, landfill gas and nuclear power, establishing a vibrant and robust power ministry that can help reform and also help in revenue collection.
\end{abstract}

Keywords: Ghana, Electricity Access, Efficiency and Performance, Electricity Demand, Electricity Supply

\section{Introduction}

Globally, energy plays an important role in the socioeconomic development and economic growth [1]. Electricity powers modern society. It lights buildings and streets and runs computers. The extensive use of electricpowered machinery plays major roles in both industrial and household production. Without electricity, economic transformation through improved productivity in manufacturing and services, technological innovations, and promoting value-addition in resource-based economies would not be possible.

Against this backdrop, the availability of electricity cannot be overemphasised as it is a catalyst for sustainable economic development, its absence may perhaps have adverse consequences which can affect society negatively. Electricity cannot be eliminated in core areas of the economy such as agriculture, industries, transportation and service sector. Due to the rise in population, quality of life and rapid industrialization, the demand for energy is expected to grow. According to [2] insufficient supply of energy will limit socioeconomic activities, restrict economic growth and negatively impact living standards.

Globally, electricity is the form of energy which is extensively used and the preferred source of energy. [3] Observes that increase in population results in high energy demand. In most developing economies particularly African and some Southeast Asia countries, electricity supply is commonly known to be unreliable which causes huge interruptions with cost implications which thus affect the efficiency of production and competitiveness. Without a doubt Africa is endowed with many energy resources such as coal, natural gas, petroleum, solar, hydro, geothermal, nuclear etc. which can be used to power its electricity capacity, yet the region's power sector is acutely weak coupled with the fact that energy consumption on a whole and electricity consumption to be precise is very low.

It is worthy to mention that Ghana's energy sector has been through series of metamorphosis: from diesel generators and stand-alone electricity supply systems (owned by industrial mines and factories), to the hydro phase, and now to a thermal complement phase powered by gas and/or light crude oil. This phase included construction of the Takoradi 
and Tema Thermal Plants and the development of the West African Gas [4]. With increases in economic growth, prevalent penetration of technology each day and rising demographic needs, Ghana is always faced with the problem of not having enough electricity to meet its increasing developmental needs. The current energy crisis has taken most Ghanaians by surprise. This should not be the case, as this is a repetitive phenomenon in the history of the country, noticeably in 1983, 1994, 1997-98, and 2006-07, with increasing severity. The 2006-07 energy crises are estimated to have cost GDP growth by about 1.5\% [5].The ongoing energy crisis threatens not only GDP growth, but also public safety and the prospect of transforming the economy.

To this end, the paper seeks to ascertain and investigate the various elements that obstruct access to reliable electricity in Ghana and also how Ghana's current power issues can be elevated to an economic suitable level. To be able to answer the aforementioned question, the current status of Ghana's electricity sector is analysed, this encompassed electricity production and consumption, fuel use, cost and energy security. The next segment examines the various challenges that impede Ghana's electricity access so as to propose steps that that can help improve access to electricity in Ghana.

The rest of the paper is set out as follows; Section 2 explicitly reviews the present electrical energy situation using Ghana as case study. The various challenges and issues pertaining to accessibility to electricity in Ghana are investigated. In the $3^{\text {rd }}$ segment, some issues were investigated where section 4 provided recommendations and section 5 concludes the paper.

\section{Study Area}

Ghana is situated in the middle of the west coast of Africa and shares borders with three French-speaking countries. It is bordered to the north by Burkina Faso (formerly Upper Volta), to the west by Cote D'Ivoire, and to the east by Togo [6]. To the south of the country lies the Atlantic Ocean and Gulf of Guinea. The Greenwich Meridian which passes through London also traverses the country at Tema. Its total area is 238,540 square kilometres (91690 square miles). Important natural resources include manganese, bauxite, gold, timber and oil. Current exploration of oil in the country also suggests that Ghana has oil in commercial quantities [7]. The Volta River is formed at the centre of the country by the confluence of the Black Volta and the White Volta. The river has served as the source of the hydroelectric power for Ghana and its neighbouring countries for many years.

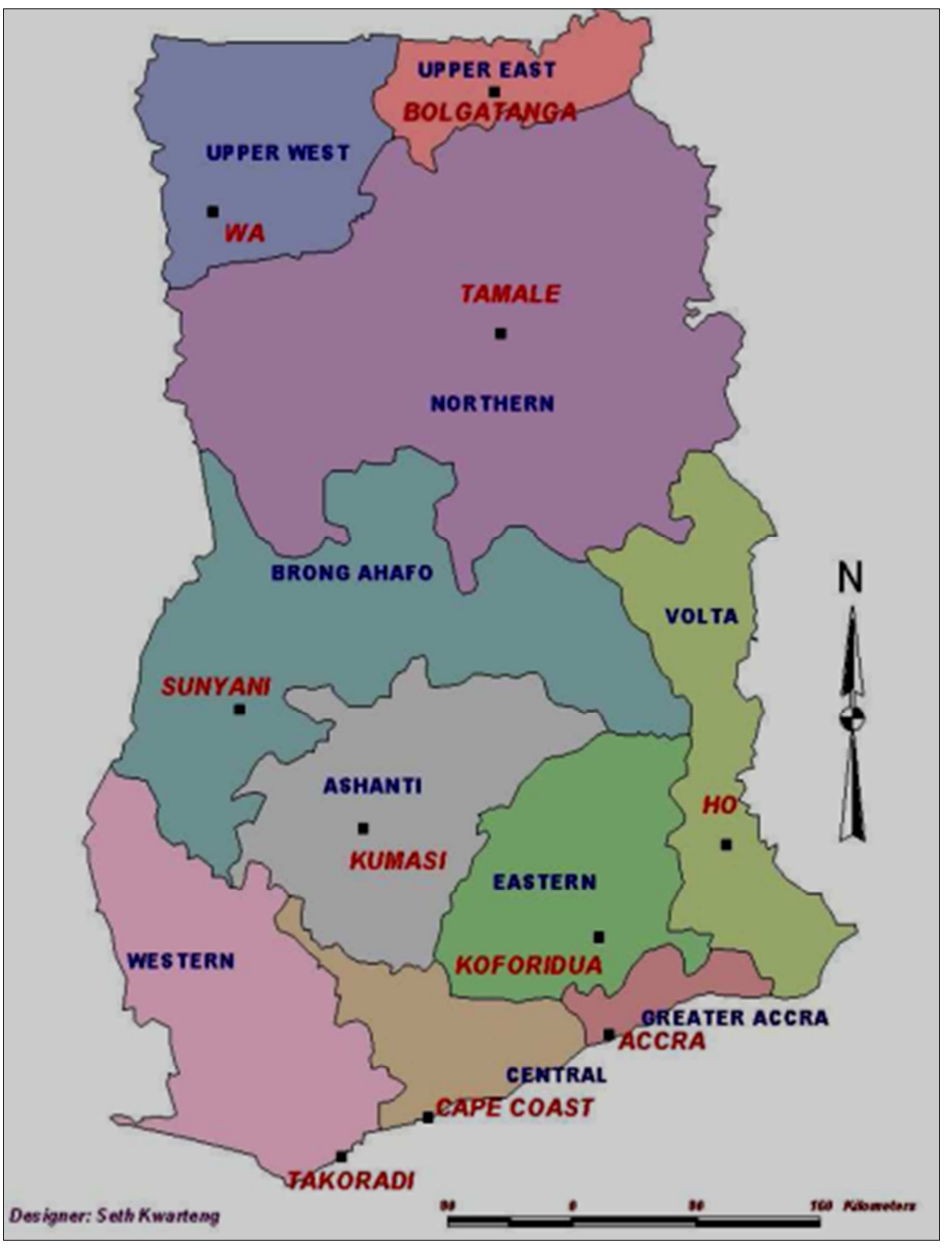

Source: http://www-pub.iaea.org/MTCD/Publications/PDF/CNPP2012_CD/countryprofiles/Ghana/Ghana.htm

Figure 1. A Map of Ghana. 
Demand for accessible electricity in Ghana has been on the rise in modern times due to increase in economic growth, development and industrial activities. [8] Opined that in 2007, electricity accounted for about $9 \%$ of Ghana's 9.50Mtoe total final energy consumption. Biomass and petroleum fuels accounted for $64 \%$ and $27 \%$ respectively of final energy consumption. Approximately, $65 \%$ of electricity generated in Ghana is from a large hydro- power station, while the remaining 35\% mostly emanate from various thermal power plants that operate on gas, diesel and light crude oil [9]

It is important to mention that, Ghana's electricity is plagued with several supply challenges. Presently, the power plants are unable to accomplish full generation capabilities due to limitations in fuel supply coupled with uncertainty of rainfall and water inflows into the hydroelectric power facilities. The high demand rate combined with intermittent hydrological shocks has caused the country to constantly rely on expensive oil and gas led methods of powering its plants. Again, Ghana's electricity prices are based on the cost of base-load hydropower priced at about $\$ 0.05 / \mathrm{kWh}$, which means that the more the country uses oil-based forms of generating power into its plants, Volta River Authority (VRA) the mandated organisation in Ghana responsible for generating electricity will incur some financial loses annually.

Again, low tariff regime which does not permit full cost recovery has also reduced the ability to expand [10]. Lack of additional capacity has been noted to be one of the reasons why there are deficiencies in Ghana's current power supply which is not able to meet its growing demand [11]. Importantly, Ghana will need a different form of capacity addition which is approximately $200 \mathrm{MW}$ annually in order to make up the increasing demand in the short and long term.

\section{Energy Supply Capacity and Trends in Ghana}

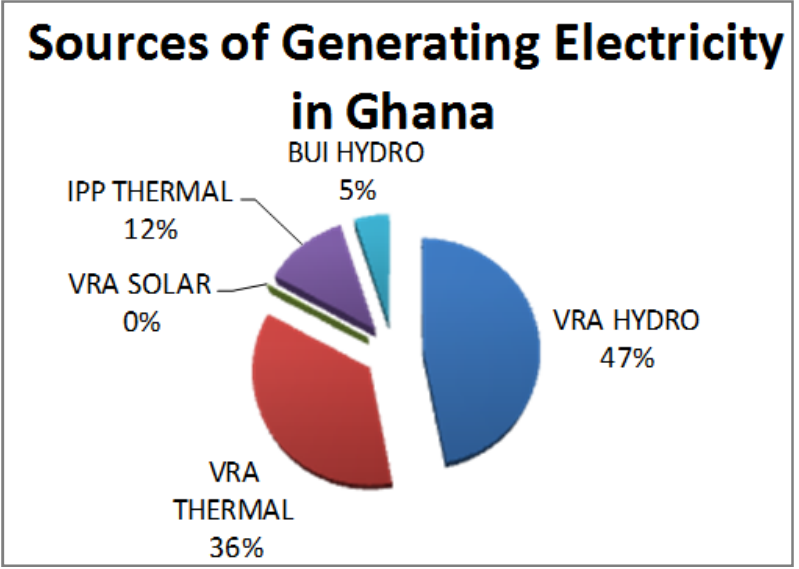

Source: Tuffour and Asamoah (2015)

Figure 2. Sources of Generating Electricity in Ghana.
The supply mix as of January 2015 shows hydro providing $52 \%$ of power needs and the rest from thermal, of which $20 \%$ can run on gas only and $80 \%$ on dual fuel generator (gas and light crude oil). Figure 2 below Ghana's installed sources of generating electricity as of January 2015.

Lack of rainfall, particularly throughout the past five years negatively exposes Ghana's historic dependence on hydro power to generate electricity via Akosombo, Kpong and Bui's installed capacity which is expected to be producing 1020, 160 and 400MW, respectively (See Table 1). The outcome is that, these plants do not perform as expected; hence they produce an output as low as percent.

Table 1. The result is that these plants operate under-capacity often as low as 75 percent.

\begin{tabular}{lll}
\hline Generating Station/Plant & $\begin{array}{l}\text { Nameplate } \\
\text { Capacity, MW }\end{array}$ & $\begin{array}{l}\text { Dependable } \\
\text { Capacity, MW }\end{array}$ \\
\hline Hydro & & \\
Akosombo & 1,020 & 900 \\
Kpong & 160 & 140 \\
Bui & 400 & 342 \\
Thermal & & \\
TAPCO & 378 & 300 \\
TICO & 252 & 200 \\
TT1PP & 126 & 110 \\
TT2PP & 49.5 & 45 \\
MRP & 85 & 80 \\
T3 & 132 & 120 \\
Sunon-Asogli & 220 & 180 \\
CENIT & 126 & 110 \\
EMBEDDED GENERATION & & \\
Genser Power-IPP & 5 & 2.1 \\
RENEWABLE & & 1.9 \\
Solar & 2.5 & $2,531.0$ \\
Total & $2,956.0$ & \\
\hline
\end{tabular}

Source: Tuffour and Asamoah (2015)

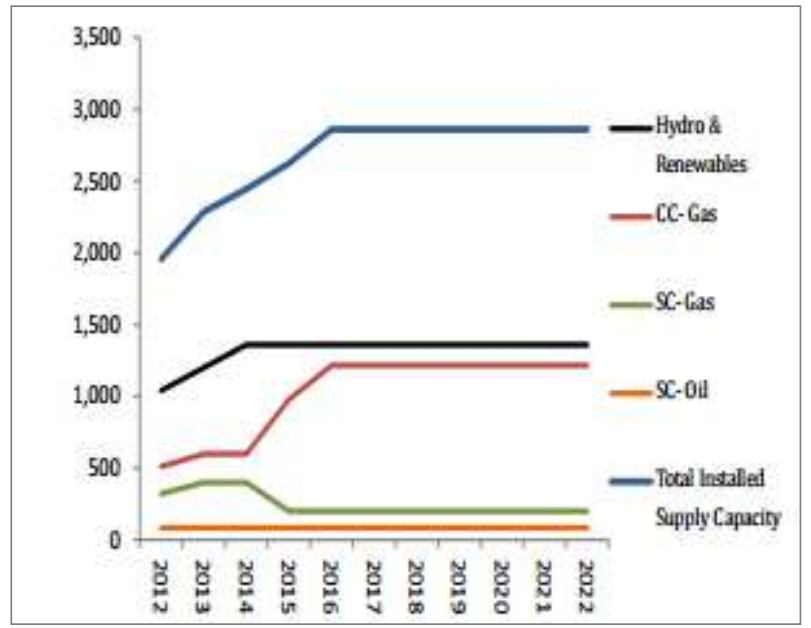

Source: Tuffour and Asamoah (2015)

Figure 3. Shows Installed Capacity Supply Capacity (MW); Expected 2012 and Projected 2013-2022 Legend-CC-Combined Cycle, SC-Single Cycle.

Also, with an installed capacity of $2,956 \mathrm{MW}$ (presently 
estimated to be about 2,846MW); even regular maintenance shutdown will worsen and widen the gap between supply and demand. As shown in Table 1, the gap between supply and demand is much bigger if projected energy generation falls short of installed capacity. Due to inadequate reserve margin in capacity requirement, projections stipulated by the Volta River Authority (VRA) do not augur well in bringing into prominence the foreseeable deficit in electricity supply. The forecast of demand and available generation capacity with a $20 \%$ reserve margin (from 2012 to 2022) reveals significant deviation between forecast figures and projected installed capacity, calling for huge investments in generation mix (see figure 3 below).

\section{Economic Cost of Failure of Electricity Supply}

The absence of unreliable electricity has direct and indirect cost implications which have huge significance as it negatively affects consumers, utilities, and the economy at large. Stipulated estimates by the World Bank shows that, directly, the cost of power outages to most African nations is usually about $2 \%$ of GDP. In the context of Ghana, GDP growth averaged around 5\% between 2000 and 2010, which implies that unreliable power supply in those years significantly affected potential economic growth. Furthermore, estimates put forward by the World Bank shows that Ghana's nominal GDP as of 2008 was approximately $\$ 16.1$ billion, meaning that deficiency in power supply possibly cost the economy more than US\$320 million annually. Figure 4 below shows Duration of Power Outages and Value Lost due to Power Outages:

This amount (US\$320 million) is enough to support the activities of Ghana Grid Company Limited (GRIDCo), the national transmitter, from 2010 to 2016 and to ensure its effective performance to consumers. Supply disruption foists considerable cost on families because of damage to appliances and the waste of food, and compromises public safety in the delivery of health care services, often with tragic consequences and the greater the technology penetration into economic activities, the greater the economic losses. Direct costs to utilities, among other things, include cost of repairing damaged equipment, process restart costs; generation revenue losses, and reduced equipment's life span.

As shown in figure 4 the duration of power outages and the estimated value loss for selected countries in lower(Kenya and Senegal), middle- (Morocco), and upper-income (Botswana and Malaysia) brackets. Ghana's average number of power outages during the 2006-07 crises was twice that of Botswana, four times of Morocco and 12 times more than Malaysia. Ghana's value loss of about $5.6 \%$ is only marginally exceeded by Kenya's $6.3 \%$. The opportunity cost linked to loss of sales and revenue, the cost of doing business resulting from insecurity, as well as the cost of on-site power equipment such as generators and erratic power supplies have negative ramifications on households and businesses. They needlessly escalate cost, and reduce income and profitability with adverse effects on government revenue targets.

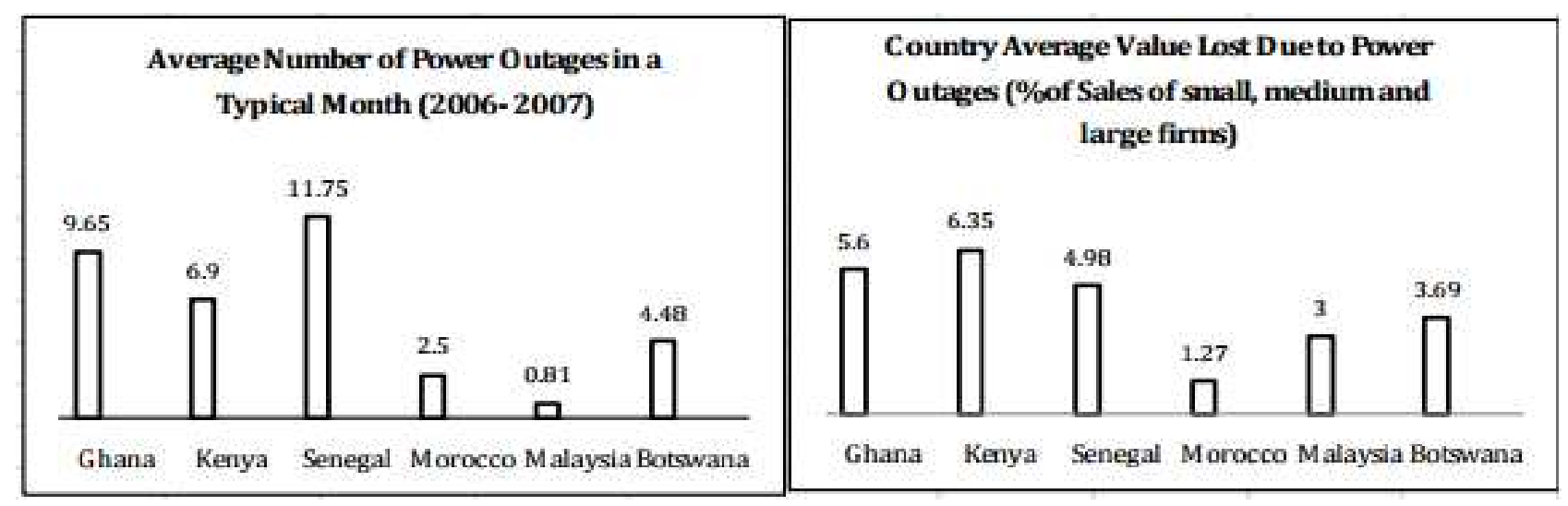

Source: Tuffour and Asamoah (2015)

Figure 4. Below shows Duration of Power Outages and Value Lost due to Power Outages.

\section{Material and Methods}

The study is qualitative in nature hence a systematic review technique which entails using explicit approach to search, appraise and synthesize available literature to satisfy the aim of the study was employed [12-13]. This method was adopted due to the nature of the paper which was broad based laying much emphasis on access to reliable electricity in Ghana. The vigorous and wide-ranging nature of systematic review helped in preventing any biasness. Also it allowed an array of data to be incorporated, thereby providing a more precise and consistent conclusions [12-13]. In broad terms, the study comprehensively dwelled on secondary sources such as books, journals, conference papers and reports that concerned themselves with the topic understudy. By employing various works on systematic review, rigorous steps were followed in order to retrieve data and provide the needed recommendations accordingly [14-15]. Finally, rigorous content analysis was done to clearly decipher the issues that concern themselves to the topic under study. 


\section{A Composition of Electricity Demand, Trends and Forecast in Ghana}

It would be noted that there has been an immense increase between 2003 and 2013. Although demand in industrial sector spiked in 2000-2002 and again in 2005 and 2006, this declined but reasonably arose between 2008 and 2011, then fell off suddenly to $1.7 \%$ in 2013 (Table 2). From a small base in 2000, annual non-residential demand growth has augmented from the usual $9 \%$ in 2000-2010; this nearly doubled to $16.5 \%$ in $2010-2013$, and doubled again to $33 \%$ in 2013. Demand in the residential sector has also increased in general by $6.2 \%$ annually during the last decade, but that rate more than doubled in 2013 alone. Figure 5: Historical Electrical Energy Demand, 2000- 2013

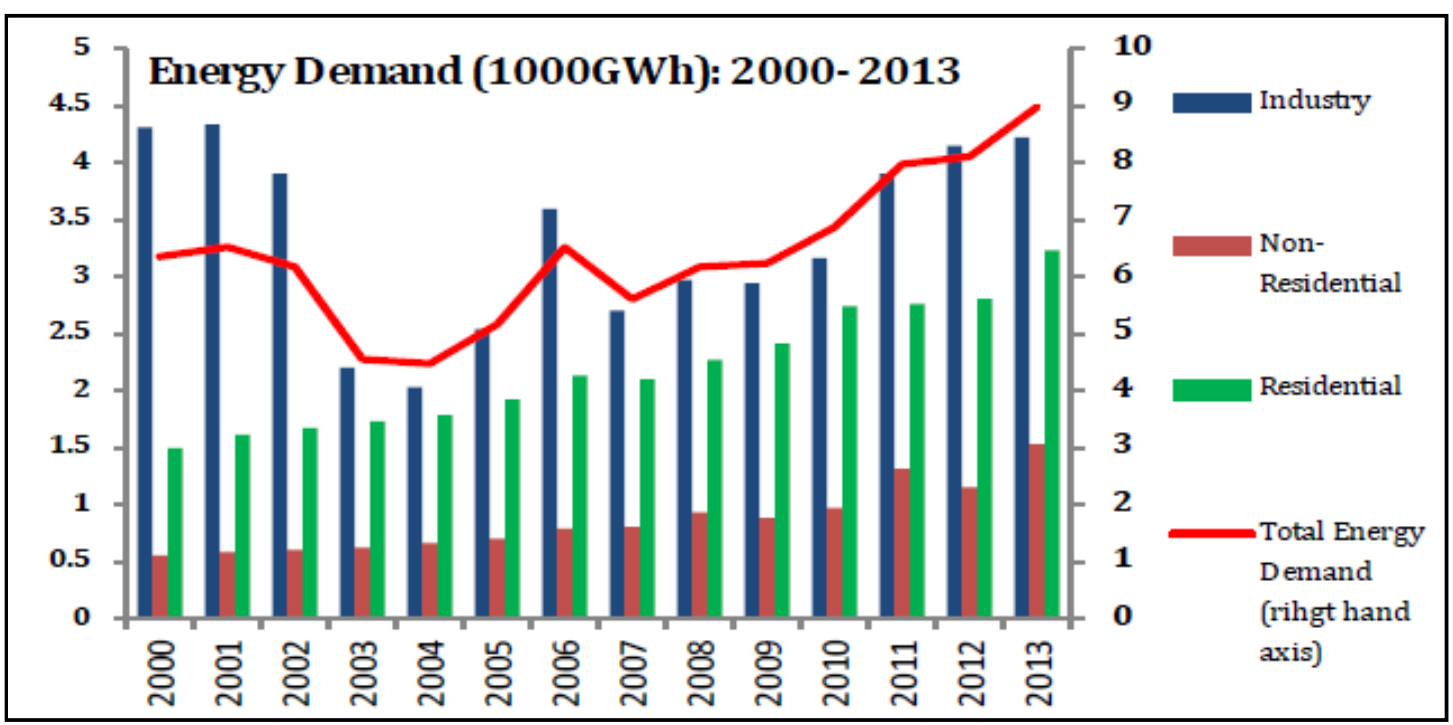

Source: Tuffour and Asamoah (2015)

Figure 5. Historical Electrical Energy Demand, 2000- 2013.

Following the trends emerging from Figure 5 and Table 2, it is worthy to mention that increases in the services sector showed that economic growth leaped from 29\% of GDP in 2000 to $51 \%$ in 2010 . This in part explains the growth in electricity demand since 2005 . That growth emerged due to development in information and telecommunication, business services and innovation in the delivery of financial services, all dependent on the availability of energy. Also, a decline in the industrial sector is explained in part by the deteriorating share of industry and specifically manufacturing in GDP; industry declined from $25 \%$ in 2000 to $19 \%$ in 2010 and manufacturing from $9 \%$ in 2005 to $6.8 \%$ in 2010 .

Table 2. Average Annual Percentage Growth in Demand.

\begin{tabular}{llll}
\hline & $\mathbf{2 0 0 0 - 2 0 1 0}$ & $\mathbf{2 0 1 0 - 2 0 1 3}$ & $\mathbf{2 0 1 3}$ \\
\hline Industry & 2.2 & 9.7 & 1.7 \\
Non-Residential & 8.9 & 16.5 & 33 \\
Residential & 6.2 & 7.8 & 15.4 \\
\hline
\end{tabular}

Source: Tuffour and Asamoah (2015)

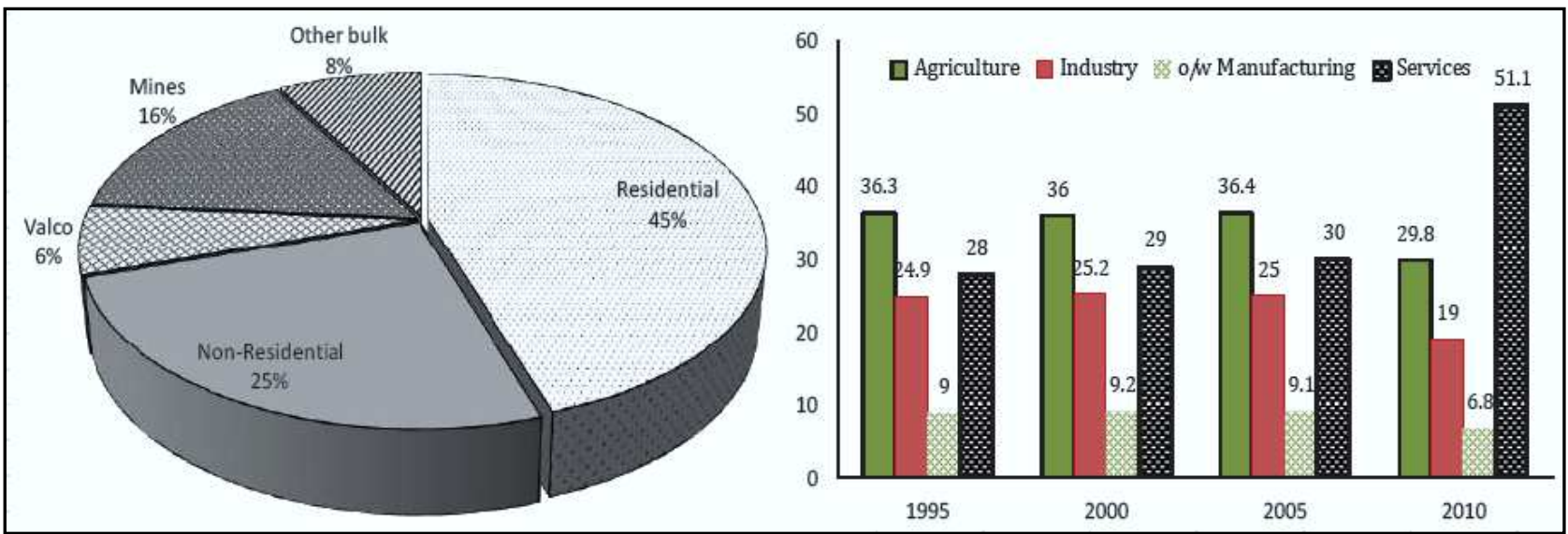

Source: Tuffour and Asamoah (2015)

Figure 6. Approximate Shares of various groups in electricity in sectoral contribution to GDP. 
In a progressive manner, Ghana's retail electricity supply has a predominantly residential and non-residential customer base (nearly $70 \%$ ). This has implications for pricing, revenue generation and the cash flow to make the industry financially viable. Figure 6 Below Provides approximate share of various groups in electricity use: 2013 and sectoral contribution to GDP.

An array of forecasts on consumption exists. For instance, in 2014, the Energy Commission (EC) indicated that peak load demand ranged between 1,900-2,200MW against the system peak load transmission of within 2,200-2,300MW. From the 2010 demand of $1,506 \mathrm{MW}$, Ghana's requirement was expected to hit 2,764MW by mid-2015. Un-met demand in 2013 was projected to be within a $240-330 \mathrm{MW}$ thermal equivalent. With growth rates in demand ranging from $6-7 \%$, it is anticipated that demand would reach between 3,598-3,898MW. A World Bank Report forecasts an additional 2,400MW of generation capacity by 2020 , which would require more than doubling Ghana's generation capacity from 2012, subject to an average GDP growth of no more than $7 \%$ per annum.

\section{Ghana's Energy in the Context of Global and Africa Energy Performance}

Table 3 below shows Ghana's energy performance, access and security both in global and continental perspective. In the overall category of Energy Architecture Performance Index (EAPI) World [16], Ghana is lagging behind the world's top 10 performers. Although Ghana's average score of 0.45 is above the SSA average of 0.28 , it falls behind considerably the global average of 0.84 . Ghana's energy access and security ranked 105 out of 124 countries assessed in 2013. Remarkably, although Ghana has considerably advanced since 2000 in terms of increasing and reforming the economy, electricity production per capita has declined. Ghana's installed generation capacity of 132MW per million population in the mid-2000s fell short of 797MW per million among middle-income African countries [17].

Table 3 Ghana versus Global Top 10 in Energy Performance and Energy Access and Security: 2013 out of 125 countries.

Table 3. The Global Energy Architecture Performance Index Report 2014, World Economic Forum. Ranking out of 125 countries.

\begin{tabular}{lllll}
\hline Country & \multicolumn{2}{l}{$\begin{array}{l}\text { Energy Architecture } \\
\text { Performance Index (EAPI) } \\
\text { 2014 }\end{array}$} & \multicolumn{2}{l}{$\begin{array}{l}\text { Energy Access and } \\
\text { Security Basket }\end{array}$} \\
\hline & Score & Rank & Score & Rank \\
\hline Norway & 0.75 & 1 & 0.96 & 1 \\
New Zealand & 0.73 & 2 & 0.85 & 5 \\
France & 0.72 & 3 & 0.81 & 18 \\
Sweden & 0.72 & 4 & 0.85 & 6 \\
Switzerland & 0.72 & 5 & 0.82 & 14 \\
Denmark & 0.71 & 6 & 0.88 & 3 \\
Colombia & 0.7 & 7 & 0.8 & 47 \\
\hline
\end{tabular}

\begin{tabular}{lllll}
\hline Country & \multicolumn{2}{l}{$\begin{array}{l}\text { Energy Architecture } \\
\text { Performance Index (EAPI) } \\
\text { 2014 }\end{array}$} & \multicolumn{2}{l}{$\begin{array}{l}\text { Energy Access and } \\
\text { Security Basket }\end{array}$} \\
\hline & Score & Rank & Score & Rank \\
\hline Spain & 0.67 & 8 & 0.78 & 30 \\
Costa Rica & 0.67 & 9 & 0.77 & 35 \\
Latvia & 0.66 & 10 & 0.77 & 36 \\
Ghana & 0.45 & 83 & 0.42 & 105 \\
\hline
\end{tabular}

Source: Tuffour and Asamoah (2015)

\section{Challenges in Ghana's Energy Sector}

Apart from weak and sluggish policies, there are serious challenges confronting Ghana's energy sector. These major challenges are as a result of increasing demand and supply shortfalls coupled with irregularities. Major factors such as poor pricing coupled with a complex web of organization and institutional restrictions have all contributed to these challenges in the energy sector.

From a demand perspective, growth in demographical needs in key areas such as health, education, urbanization, rapid rural electrification, and technological advancement on daily basis have also played a role in generating these challenges. Then, in addition to these factors are issues of illegal connections, and problems of metering, billing and collection. While the preceding factors are obvious due to growth in population and high standards of living, it would be noted that factors in the second category work against the capability to generate revenue. Also, due to the exponential growth predominantly in the residential and non-residential customer base $(70 \%)$ of the energy sector, as high energy sensitive production activities (manufacturing and mining) decline, makes economic pricing, strong billing, and the collection system critical to the financial viability of the industry.

Nonetheless, in recent years, the Ghanaian government have kept in check Electricity pricing by regulators. However, pricing for end users does not reflect the cost of inputs neither does it reveal the realism of the changing mix of the inputs away from a fairly cheaper hydro to gas and light crude oil. In addition to wrong pricing, the idea of subsidising some targeted consumers has damaged the financial capabilities of the Electricity Corporation of Ghana (ECG), a major supplier of Ghana's electricity at the retail level. Also, the absence of a good residential address system and a very weak billing of residential customers who consume about $45 \%$ of the electricity supplied suggest that commercial customers who only consume $25 \%$ are easily identified and are made to bear majority of burden in terms of paying bulk of ECG revenues.

In terms of supply, there are two main obstacles: insufficient supply and irregular supply. Factors such us ; poor investment which turns to obstruct generating capacity; failure to attract independent investors due to low incentives; poor governance and regulatory framework, and bureaucracy; declining hydro capacity; and failure to enhance 
the supply mix account for the inadequate supply. Also, input tariffs have merged with real cost coupled with poor pricing at the user end, this has intensified the financial incapabilities of both generating and distribution companies. Not only does this cause a decline in production per capita, but high transmission and distribution losses also causes a decline in supply significantly which results in short of the production capacity. Also, inaccessible supply of electricity originates from the lack of maintenance of generating, transmission, and distribution facilities, and the poor performance of ECG as the primary retailer.

Although there are independent power producers in Ghana (IPPs), there seems to be difficulty in catching the attention of new IPPs. Presently, issues pertaining to gas availability to power plants are a major blockade for prospective IPPs. In this light, it wouldn't be surprising if Ghana does not have access to sufficient supply of gas for power generation until 2015, or maybe even 2018. Similarly, poor governance and rigid regulatory framework is not attractive to IPPs. To start with, prospective IPPs do not have faith in the usual off taker ECG as the organization is in financial crises; and there are genuine concerns about its ability to pay power producers.

Again, there are concerns regarding matters of uncertainty about procedures and regulations. Finally, the IPP development process is awkward and takes a lot of time as presently Ghana does not have a single-window system for IPPs. Thus, it is important that the Government removes these barriers to IPPs in power generation. This process must be led by the sector Ministry (now Ministry of Power) by employing a full-time, high-level IPP manager to take on this duty, in association with the Ministry of Finance's (MoF's) Public Private Partnership unit. With VRA as a key actor on the supply side, Figure 7 above sums up the nature of the challenges on both the inputs side and the output side and, together with the challenges of ECG and the Northern Electricity Distribution Company (NEDCo), support each other in a vicious circle of a financially unsustainable system.

\subsection{Lack of a Credible Off-taker}

Presently, to be able to obtain licenses, procedures in the power sector makes provision for only "bulk customers," who are free to secure their power needs directly from wholesale suppliers via transmission services provided by an Independent System. Prospective off-takers of power are ECG, NEDCo, the mining companies, and other licensed bulk customers. VRA, which was Ghana's first Independent Power Provider (IPP) project, functioned as both owner and off-taker. Its dual functions were modernized as the rationale for the project was to complement hydro generation, and allow the country to optimize the yield from hydro and nonhydro sources. Nevertheless, VRA has since been reluctant to sign power purchase agreements (PPAs) with IPPs, because it regards IPPs as competing rather than complementary generation entities.

Apart from ECG, no other prospective buyer has signed a PPA to off-take power from any of the IPPs. Out of the four PPAs, only three underpinning IPP development in Ghana has ECG as the off taker, while the other has VRA as the concurrent co-owner and off taker. The IPPs that have tried to penetrate the Ghanaian market have reported complexity in securing PPAs with other organizations.

\subsection{ECG's Commercial Performance Needs Improvement}

Due to low residential tariffs, most of ECG's revenues are generated from non-residential consumers who account for $56 \%$ of sales revenue, even though they account for only $12 \%$ of ECG's unit sales. Importantly, this cross-subsidy foists a major burden on commercial customers. Bearing in mind that PURC has failed to increase retail tariffs, it is reported that ECG incurred losses of US\$44 million in 2012, and US\$60 million in 2013. As indicated in a 2009 World Bank report (Box 1), ECG's losses are worsened by high technical losses; poor revenue collection, from both Government entities and private consumers; and rising dollar-denominated payment obligations. Tariff policies that provide subsidies to consumers have damaged the financial health of ECG and NEDCo.

\subsection{Subsidies and Pricing}

Going forward, for Ghana's power sector to be financially sustainable there is the need for the price of electricity to allow for full cost recovery across the entire value chain. Nonetheless, for a long time, prices paid by consumers of electricity have been below the cost of supply. The relatively low tariffs have made the sector unappealing to other stockholders. Since 2004, Government has virtually spent US\$900 million on fuel subsidies for VRA. This is more than the cost of building the Bui Dam. Transferring this expenditure on infrastructure would have been of much more value in the long run.

\subsection{Gas Pricing}

Although the basic principles of Gas Pricing Policy was approved in mid-2012 by cabinet, based on a comprehensive study carried out by international consultants, Government has not been published its Gas Pricing Policy. Hence, the study advocates that gas pricing should indicate gas supply distributing priorities between different sectors in the market, such as power generation, petrochemicals, etc. Also, it established targets for maximum supply costs in the various sectors of the market and minimum gas prices for associated and non-associated gas.

\subsection{Poor Revenue Collection}

At the beginning of the year, the minster responsible for power established a Task Force to collect arrears of nearly GHc500 million owed ECG. As indicated a 2005 report, the relatively poor financial health of ECG and NEDCo stems from the poor payment culture of Government institutions as well as private consumers. To alleviate the poor payment culture, thus ECG must accelerate the fitting of prepaid meters at the premises of consumers. Also, disciplinary measures must be put in place as a warning to the theft of electricity through bypassing of meters. 


\subsection{The Unproductive Clearinghouse Initiative}

A cross-debt clearinghouse organization was set up to manage the inter-utility and Government debts, it encompasses VRA, ECG, NEDCo, and Ghana Water Company Ltd., with Government represented by Ministry of Finance (MoF). Quarterly, they must meet to reconcile the cross-indebtedness of the participants and net off such debts where suitable. However, this has not been effective, due to their inability to enforce payment expected from the net debtors. Since the MoF has not received any settlement payment from these institutions, and given the way that central banks make interbank clearing enforceable, the clearinghouse initiative is dependent on voluntary compliance. None-payment meant that VRA, which generates nearly $80 \%$ of its profits from these other clearinghouse members, is continually owed, with a build-up of receivables. In 2012 the MoF suspended the clearinghouse mechanism, but no other payment system has been instituted. The debt levels and the matrix of receivables of the utilities have negative repercussions for the utilities' operations and financial viability. While necessary, clearance of state arrears by the Government is not sufficient in the absence of better arrangements to prevent recurrence of the arrears.

\section{Going Forward}

\subsection{The Future of Power Mix}

Ghana gas: Ghana's power mix is going through metamorphoses from hydro to thermal, granting that the demand for power in Ghana is growing at a rate of $10 \%$ annually. It is wise to explore all potential power sources, including LNG, solar (for concentrated solar power), landfill gas, and nuclear. At best, Ghana Gas can supply gas that can generate $500 \mathrm{MW}$, which could raise Ghana's installed capacity from about 2,900 MW currently to about 3,400 MW, but still short of the expected installed capacity of 5,000 MW in 2016.

\subsection{Future of WAGP and Challenges of Imported Gas}

Guaranteeing acceptable and safe supply of natural gas is an essential determinant to improving the accessibility and affordable cost of power to both VRA and IPPs. Ghana has two different gas resources to turn to: domestic gas resources and Nigeria. Yet, sporadic supply disruptions on the West Africa Gas Pipeline (WAGP) have often led to serious nearterm gas scarcity. The just agreed increase in the price of gas from WAGP could cause the supply of relatively high volumes of gas from Nigeria. This expectation, however, may only happen if other factors - such as militancy in the Niger Delta of Nigeria and efficient functioning of the value chain in the extraction, transmission and delivery of gas to Aboadze and Sunon-Asogli power plants - are stabilized.

\subsection{The New Power Ministry}

Clearly, the two key issues that are likely to influence the organizational dynamics of the power sector are the creation of a new Ministry of Power in December 2014, and the conclusion of agreements with the Millennium Challenge Corporation (MCA) for a US\$500m investment in the energy sector. The new Ministry must rapidly establish urgent reforms, particularly to ECG in its operational, technical and management competence. Further to this, the Ministry must critically focus on the generation, supply, and efficiency of power in order to meet economic demands.

\section{Conclusion}

Access to reliable electricity is a major determinant which enhances rapid development in most economies in the world. Ghana's access to electricity has been below the economically acceptable level and has not improved in recent times due to some challenges. As highlighted in the paper, these challenges include; low efficiency and performance, security of fuel source for power generation, data inadequacy, regulatory barriers, lack of institutional arrangement, poor grid structure, dilapidated transmission and distribution network, low financial investment, lack of policy and project continuity. In this light a way forward has been presented in order to improve electricity access in Ghana. This much anticipated improvement may not be instantaneous but a gradual process.

\section{References}

[1] Emodi, V.N., Yusuf, S.D. and Boo, K.-J. (2014) The Necessity of the Development of Standards for Renewable Energy Technologies in Nigeria. Smart Grid and Renewable Energy, (5) 259-274.

[2] Oseni., M. (2012) Households's access to electricity and energy consumption pattern in Nigeria. Renewable and Sustainable Energy Reviews, 16 (1).

[3] Oyedepo, S., O. (2013) Energy in Perspective of Sustainable Development in Nigeria. Sustainable Energy (2) 14-25.

[4] Energy Commission (2014) Energy (Supply and Demand) Outlook for Ghana, April 2014. Foster, Vivien and Nataliya Pushak, Ghana's Infrastructure: Continental Perspective, Washington, DC: World Bank Policy Research Paper No. 5600,2011 .

[5] World Bank, (2011) Energizing Economic Growth in Ghana: Making the Power and Petroleum Sectors Rise to the Challenge, Energy Group Africa Region.

[6] Boateng, E. A. (1966) a Geography of Ghana 2nd Edition, Cambridge University Press, Cambridge.

[7] Government of Ghana (GOG) (2010) Budget statement for the year 2008 Ghana Official Portal [Online] accessed at http://Ghana.gov.gh/Ghana/budget_statements.jsp on 13th March 2015.

[8] Duku M, H. and Hagan E, B. (2011) A comprehensive review of biomass resources and bio fuels potential in Ghana. Renewable Sustainable Energy Review (15) 404-15. 
[9] Ghana Energy Commission (2011) Energy supply and demand outlook for Ghana: Ghana Energy Commission.

[10] USAID (1999) an energy roadmap of Ghana: from crisis to the fuel for economic freedom. A report by the US Government Interagency Team.

[11] Brew-Hammond A, Kemausour F (2007) Energy crisis in Ghana: drought, technology or policy. Kwame Nkrumah University of Science and Technology (KNUST), Ghana.

[12] Victor, L., (2008) Systematic reviewing. Social Science Update, 58: 1-4.

[13] Akobeng, A. K., (2005) Understanding systematic review and data analysis. Achieves of Disease in Childhood, 90(6), 845848 .
[14] Victor, L., (2008) Systematic reviewing. Social Science Update, 58: 1-4.

[15] Khan, K. S., Kunz, R., Kleijnen, J., and Antes, D., (2003) Five steps to conducting a systematic review. Journal of the Royal Society of Medicine, 96(3), 118-121.

[16] World Economic Forum (2014) The Global Energy Architecture Performance Index Report.

[17] USG-GoG Technical Team, August (2011) World Bank, Energizing Economic Growth in Ghana: Making the Power and Petroleum Sectors Rise to the Challenge, Energy Group Africa Region. 